\author{
N. Shaat - E. Karlsson - Å. Lernmark - S. Ivarsson • \\ K. Lynch · H. Parikh · P. Almgren · K. Berntorp · \\ L. Groop
}

\title{
Common variants in MODY genes increase the risk of gestational diabetes mellitus
}

Received: 6 January 2006 / Accepted: 28 February 2006 / Published online: 26 April 2006

C) Springer-Verlag 2006

\begin{abstract}
Aims/hypothesis: Impaired beta cell function is the hallmark of gestational diabetes mellitus (GDM) and MODY. In addition, women with MODY gene mutations often present with GDM, but it is not known whether common variants in MODY genes contribute to GDM. Subjects and methods: We genotyped five common variants in the glucokinase ( $G C K$, commonly known as $M O D Y 2)$, hepatocyte nuclear factor 1- $\alpha$ (HNF1A, commonly known as MODY3) and 4- $\alpha$ (HNF4A commonly known as $M O D Y 1$ ) genes in 1,880 Scandinavian women (648 women with GDM and 1,232 pregnant non-diabetic control women). Results: The A allele of the $G C K-30 \mathrm{G} \rightarrow \mathrm{A}$ polymorphism was more common in GDM women than in control subjects (odds ratio [OR] 1.28 [95\% CI 1.06-1.53], $p=0.008$, corrected $p$ value, $p=0.035$ ). Under a recessive model [AA vs $\mathrm{GA}+\mathrm{GG}$ ], the OR increased further to $2.12(95 \%$ CI $1.21-3.72$, $p=0.009$ ). The frequency of the $\mathrm{L}$ allele of the HNF1A I27L polymorphism was slightly higher in GDM than in
\end{abstract}

Electronic Supplementary Material Supplementary material is available for this article at http://dx.doi.org/10.1007/s00125-0060258-8

N. Shaat $(\bowtie) \cdot$ E. Karlsson · A. Lernmark · K. Lynch ·

H. Parikh · P. Almgren · K. Berntorp · L. Groop

Department of Clinical Sciences/Diabetes and Endocrinology,

Malmö University Hospital, Lund University,

Malmö, Sweden

e-mail: nael.shaat@med.lu.se

Tel.: +46-40-391214

Fax: +46-40-391222

Å. Lernmark

Robert H. Williams Laboratory, University of Washington,

Seattle, WA, USA

S. Ivarsson

Department of Paediatrics, Malmö University Hospital, Lund University,

Malmö, Sweden

L. Groop

Department of Medicine, Helsinki University Hospital,

Helsinki, Finland controls (1.16 [95\% CI 1.001-1.34], $p=0.048$, corrected $p$ value, $p=0.17)$. However, the OR increased under a dominant model (LL+IL vs II; 1.31 [95\% CI 1.08-1.60], $p=0.007)$. The rs2144908, rs2425637 and rs 1885088 variants, which are located downstream of the primary beta cell promoter (P2) of $H N F 4 A$, were not associated with GDM. Conclusions/interpretation: The $-30 \mathrm{G} \rightarrow \mathrm{A}$ polymorphism of the beta-cell-specific promoter of $G C K$ and the $127 \mathrm{~L}$ polymorphism of $H N F 1 A$ seem to increase the risk of GDM in Scandinavian women.

Keywords $-30 \mathrm{G} \rightarrow \mathrm{A} \cdot G C K \cdot \mathrm{GDM} \cdot \mathrm{Genes} \cdot \mathrm{Gestational}$ diabetes mellitus · Glucokinase - HNF1A - HNF4A - I27L · MODY $\cdot$ Polymorphism $\cdot$ Scandinavian

Abbreviations DBS: dried blood spots - ESM: electronic supplementary material - GDM: gestational diabetes mellitus - GCK: glucokinase gene $\cdot H N F 1 A$ : hepatocyte nuclear factor-1 $\alpha$ gene $\cdot H N F 4 A$ : hepatocyte nuclear factor- $4 \alpha$ gene $\cdot$ OR: odds ratio

\section{Introduction}

Gestational diabetes mellitus (GDM) is the most common metabolic disorder during pregnancy, and is defined as glucose intolerance with onset or first recognition during pregnancy [1]. The prevalence of GDM ranges from 0.6 up to $15 \%[2,3]$, and the frequency has increased in several populations during the last decade $[4,5]$. Impaired beta cell function and insulin resistance characterise pregnancy complicated by GDM [6]. However, when insulin secretion is adjusted for the degree of insulin resistance, women with GDM have a severe reduction in beta cell function compared with normal pregnant women [7]. This beta cell dysfunction seems to persist in women with a history of GDM post partum $[6,8]$.

MODY is a clinically and genetically heterogeneous monogenic disease characterised by an autosomal dominant mode of inheritance, early onset (usually before the age of 25 years) and pancreatic beta cell dysfunction [9]. 
Mutations in the genes encoding the glycolytic enzyme glucokinase ( $G C K$, commonly known as MODY2) and the transcription factors hepatocyte nuclear factor 4- $\alpha$ (HNF4A commonly known as MODY1) and 1- $\alpha$ (HNF1A, commonly known as $M O D Y 3$ ), insulin promoter factor 1 (IPF1, commonly: MODY4), transcription factor 2 (TCF2, commonly: MODY5) and neurogenic differentiation factor 1 (NEUROD1, commonly: MODY6) have been shown to cause MODY [9]. The most common forms of the disease are MODY2 and MODY3, which account for $20-65 \%$ of all MODY subtypes in Europe [10,11]. Mutations in the genes involved in MODY1 are less frequent and may account for $5 \%$ of subjects with MODY [10, 11], while MODY4-6 are very rare $[9,10]$.

Women with mutations in $G C K$ [12-17] or HNF1A [16, 18] often present with GDM. In addition, mutations in IPFI have been reported in women with GDM [16, 19]. Common variants in MODY genes, including $G C K-30 \mathrm{G} \rightarrow \mathrm{A}[20$, 21] and $H N F 1 A$ I27L [22] variants as well as the rs 2144908 , rs2425637 and rs1885088 variants in HNF4A [23-25], have been associated with beta cell dysfunction, diabetes or related traits.

Since rare mutations in MODY genes are associated with GDM as well as beta cell dysfunction is the hallmark of GDM and MODY, we hypothesised that common variants in MODY genes would also increase the risk of GDM.

Since a comprehensive screening of MODY genes has already been performed in Caucasian patients with type 2 diabetes [26-28] (Winckler W, Weedon M, Graham R et al. unpublished data), we did not perform such screening of these genes and regulatory regions in our study subjects. Instead, we selected five variants in the MODY1-3 genes (i.e. the most common MODY subtypes in Europe) that fulfilled the following criteria: (1) allele frequency of at least $\sim 15 \%$ in order to have sufficient power to detect a relatively modest odds ratio $(\mathrm{OR} \sim 1.3)$; (2) evidence of association with beta cell dysfunction and/ or type 2 diabetes or related traits; and (3) for HNF4A variants, to represent distinct haplotype blocks as measured by linkage disequilibrium in Caucasians [23, 28]. We genotyped the $G C K-30 \mathrm{G} \rightarrow \mathrm{A}, H N F 1 A$ I27L and HNF4A (rs2144908, rs2425637 and rs1885088) variants in a case-control study of 648 unrelated Scandinavian women with GDM and 1,232 unrelated Scandinavian pregnant non-diabetic controls.

\section{Subjects and methods}

Study population

All pregnant women are routinely offered a $75 \mathrm{~g}$ OGTT at 27-28 weeks of pregnancy in southern Sweden (Skåne). Women at high risk (previous GDM or a family history of diabetes) are also offered a 75 g OGTT at 12-13 weeks. The tests are performed in the local maternity health-care clinics, using HemoCue devices (HemoCue, Ängelholm, Sweden) for capillary whole blood analysis. GDM is defined as a $2 \mathrm{~h}$ capillary glucose concentration (double test) of at least $9 \mathrm{mmol} / \mathrm{l}$ according to the proposal by the Diabetic Pregnancy Study Group of the European Association for the Study of Diabetes [29].

The phenotypic characteristics of the majority of the participants in the present study have been reported earlier [30]. Detailed OGTT data during pregnancy were available only for a small subset of GDM women who were prospectively followed with repeated OGTTs [31]. Briefly, we selected 1,880 unrelated Scandinavian women (648 women with GDM and 1,232 pregnant non-diabetic controls). Women with GDM were recruited from Malmö or Lund University Hospitals during the period from March 1996 until December $2003(n=226)$ as well as among women participating in the Diabetes Prediction in Skåne (DiPiS) study, which is a prospective, longitudinal study for the prediction of type 1 diabetes in all newborn infants in southern Sweden during the period from September 2000 to August $2004(n=422)$ [32]. All pregnant non-diabetic controls $(n=1,232)$ were ascertained from the DiPiS study. Both GDM groups and the control group are considered to be homogeneous since the GDM women who were recruited from Malmö or Lund hospitals were referred from maternity health-care clinics and underwent the same screening procedure as the DiPiS subjects. In addition, the study groups were recruited during a similar period, and the population in southern Sweden is very homogeneous. All women were Scandinavians. Informed voluntary consent was obtained from all study subjects. The study was approved by the ethics committee of Lund University.

Genetic analyses

\section{DNA extraction and template preparation}

Total DNA was isolated from peripheral blood lymphocytes or blood samples were collected as dried blood spots (DBS) on filters (Grade 2992 filters; Schleicher and Schuell, Dassel, Germany).

For DBS samples, initially a template PCR was carried out to amplify the region of interest using the primers listed in Electronic Supplementary Material (ESM), Table 1.

The template PCR was performed with an initial two cycles at $4^{\circ} \mathrm{C}$ for $30 \mathrm{~s}$ followed by $98^{\circ} \mathrm{C}$ for $3 \mathrm{~min}$, followed by holding at $80^{\circ} \mathrm{C}$ while the PCR mix was added. Then the PCR was continued with an initial denaturation $\left(94^{\circ} \mathrm{C}\right.$ for $5 \mathrm{~min}$ ), followed by 45 cycles of denaturation $\left(94^{\circ} \mathrm{C}\right.$ for $30 \mathrm{~s}$ ), annealing $(30 \mathrm{~s})$ and extension $\left(72^{\circ} \mathrm{C}\right.$ for $\left.30-60 \mathrm{~s}\right)$, followed by final extension $\left(72^{\circ} \mathrm{C}\right.$ for $\left.10 \mathrm{~min}\right)$. PCR amplification was carried out with a $3 \mathrm{~mm}$ DBS in a total volume of $40 \mu \mathrm{l}$ containing $1 \times$ Pharmacia Amersham buffer (Amersham Pharmacia Biotech, Uppsala, Sweden) $(G C K-30 \mathrm{G} \rightarrow \mathrm{A}$ [rs1799884] and HNF4A [rs2425637 and rs1885088]) or $1 \times\left(\mathrm{NH}_{4}\right)_{2} \mathrm{SO}_{4}$ buffer $\left(16 \mathrm{mmol} / 1\left(\mathrm{NH}_{4}\right)_{2}\right.$ $\mathrm{SO}_{4} ; 67 \mathrm{mmol} / 1$ Tris [pH 8.8]; 0.01\% Tween 20) (HNF1A I27L [rs1169288] and HNF4A [rs2144908]), 4-8 nmol of each dNTP (MBI Fermentas, St Leon-Rot, Germany), $20 \mathrm{pmol}$ of each primer, $60 \mathrm{nmol} \mathrm{MgCl}(G C K-30 \mathrm{G} \rightarrow \mathrm{A}$, HNF1A I27L and HNF4A [rs2144908 and rs2425637]), 
betaine (Sigma-Aldrich Sweden, Stockholm, Sweden) $(20 \mu \mathrm{mol}: G C K-30 \mathrm{G} \rightarrow \mathrm{A}$ and $H N F 4 A$ [rs1885088]; 30 umol: HNF4A [rs2425637]) and 1-1.5 U Taq polymerase (New England Biolabs, Beverly, MA, USA).

\section{Genotyping}

SNP genotyping was carried out using the TaqMan allelic discrimination assay or RFLP.

For the TaqMan allelic discrimination assay on an ABI Prism 7900 Sequence Detection System (Applied Biosystems, Foster City, CA, USA), we used $2 \mu \mathrm{l}$ (5-10 ng) of DNA or $2 \mu \mathrm{l}$ of template PCR (for DBS samples as described above) according to the manufacturer's instructions. Primers and probes were designed using Assays-byDesign (Applied Biosystems). The primers and probes used are listed in ESM Table 2.

Since the TaqMan assay did not work out properly for the $G C K-30 \mathrm{G} \rightarrow \mathrm{A}$ variant on DBS samples, genotyping was carried out using RFLP. The template PCR (see description of template PCR above) product was digested with the enzyme Alw21I (MBI Fermentas, St Leon-Rot, Germany) at $37^{\circ} \mathrm{C}$ for $4 \mathrm{~h}$. PCR products were separated on $2 \%$ agarose gel (SeaKem, Rockland, ME, USA) and stained with ethidium bromide to visualise the fragments using UV light.

\section{Genotyping quality control}

The genotyping success rate was $97.5 \%$ for cases $(G C K \quad-30 \mathrm{G} \rightarrow \mathrm{A}, \quad 99.1 \% ; \quad H N F 1 A \quad \mathrm{I} 27 \mathrm{~L}, \quad 94.8 \%$; rs2144908, 96.8\%; rs2425637, 99.2\%; rs 1885088 , $97.5 \%)$ and $99.0 \%$ for controls $(G C K-30 \mathrm{G} \rightarrow \mathrm{A}, 99.8 \%$; HNF1A I27L, 98.5\%; rs2144908, 98.9\%; rs2425637, $99.8 \%$; rs $1885088,97.8 \%)$. The genotyping error rate was determined to be $<0.3 \%$ using $943(10 \%)$ duplicate genotypes and 89 double samples (i.e. GDM women who had both peripheral blood DNA and DBS or two DBS spotted at different deliveries). In the control group, all SNPs conformed to Hardy-Weinberg equilibrium ( $\chi^{2}$ test, $p>0.05$ ), apart from HNF4A rs2144908, which deviated mildly ( $p=0.027$ ). Since the measures described above rule out possible genotyping errors, this deviation might be due to chance variation.

\section{Statistical analyses}

We used $\chi^{2}$ analysis to test for differences in allele and genotype frequencies between GDM and control groups. Logistic regression analysis was used to calculate the OR and $95 \%$ CI. ANOVA was used to test the significance of differences in continuous variables, such as age, between GDM and control groups using the Number Cruncher Statistical Systems (NCSS, Kaysville, UT, USA). Age was

Table 1 Genotype and allele distributions and corresponding odds ratios for GDM

\begin{tabular}{|c|c|c|c|c|c|c|}
\hline SNP (rs number) & $\begin{array}{l}\text { Genotype } \\
\text { or allele }\end{array}$ & GDM $n(\%)$ & Controls $n(\%)$ & $\begin{array}{l}\text { OR }(95 \% \mathrm{CI}) \\
\text { for GDM, additive } \\
\text { model/allelic effect }\end{array}$ & $\begin{array}{l}\text { OR }(95 \% \mathrm{CI}) \\
\text { for } \mathrm{GDM}, \\
\text { recessive model }\end{array}$ & $\begin{array}{l}\text { OR }(95 \% \mathrm{CI}) \\
\text { for GDM, } \\
\text { dominant model }\end{array}$ \\
\hline \multirow{4}{*}{$\begin{array}{l}G C K-30 \mathrm{G} \rightarrow \mathrm{A} \\
(\mathrm{rs} 1799884)\end{array}$} & GG & $435(67.8)$ & $889(72.3)$ & & & \\
\hline & GA & $181(28.2)$ & $316(25.7)$ & $1.17(0.94-1.45)$ & & \\
\hline & $\mathrm{AA}$ & $26(4.0)$ & $24(2.0)^{\mathrm{a}}$ & $2.21(1.26-3.90)^{\mathrm{b}}$ & $2.12(1.21-3.72)^{\mathrm{b}}$ & $1.24(1.01-1.53)^{\mathrm{C}}$ \\
\hline & A & $233(18.1)$ & $364(14.8)$ & $1.28(1.06-1.53)^{\mathrm{b}}$ & & \\
\hline \multirow{4}{*}{$\begin{array}{c}H N F 1 A \text { I27L } \\
(\text { rs1169288) }\end{array}$} & II & $242(39.4)$ & $559(46.1)$ & & & \\
\hline & IL & $298(48.5)$ & $508(41.8)$ & $1.36(1.10-1.67)^{\mathrm{b}}$ & & \\
\hline & LL & $74(12.1)$ & $147(12.1)^{\mathrm{c}}$ & $1.16(0.85-1.60)$ & $0.99(0.74-1.34)$ & $1.31(1.08-1.60)^{\mathrm{b}}$ \\
\hline & $\mathrm{L}$ & $446(36.3)$ & $802(33.0)$ & $1.16(1.001-1.34)^{\mathrm{c}}$ & & \\
\hline \multirow{4}{*}{$\begin{array}{l}H N F 4 A \\
(\text { rs2144908) }\end{array}$} & GG & $425(67.8)$ & $854(70.1)$ & & & \\
\hline & GA & $167(26.6)$ & $316(25.9)$ & $1.06(0.85-1.32)$ & & \\
\hline & $\mathrm{AA}$ & $35(5.6)$ & $48(4.0)$ & $(0.93-2.30)$ & $1.44(0.92-2.25)$ & $1.12(0.91-1.37)$ \\
\hline & $\mathrm{A}$ & 237 (18.9) & $412(16.9)$ & $1.14(0.96-1.37)$ & & \\
\hline \multirow{4}{*}{$\begin{array}{l}H N F 4 A \\
(\text { rs2425637) }\end{array}$} & GG & $159(24.7)$ & $317(25.8)$ & & & \\
\hline & GT & $310(48.2)$ & $617(50.2)$ & $1.00(0.79-1.27)$ & & \\
\hline & TT & $174(27.1)$ & $295(24.0)$ & $1.18(0.90-1.54)$ & $1.17(0.94-1.46)$ & $1.06(0.85-1.32)$ \\
\hline & $\mathrm{T}$ & $658(51.2)$ & $1,207(49.1)$ & $1.09(0.95-1.24)$ & & \\
\hline \multirow{4}{*}{$\begin{array}{l}\text { HNF4A } \\
\text { (rs1885088) }\end{array}$} & GG & $412(65.2)$ & $791(65.6)$ & & & \\
\hline & GA & $199(31.5)$ & $354(29.4)$ & $1.08(0.87-1.33)$ & & \\
\hline & $\mathrm{AA}$ & $21(3.3)$ & $60(5.0)$ & $0.67(0.40-1.12)$ & $0.66(0.40-1.09)$ & $1.02(0.83-1.25)$ \\
\hline & $\mathrm{A}$ & $241(19.1)$ & $474(19.7)$ & $0.96(0.81-1.14)$ & & \\
\hline
\end{tabular}

${ }^{\mathrm{a}}$ Differences in genotype frequencies between women with and without GDM $(p=0.010$ for $G C K-30 \mathrm{G} \rightarrow \mathrm{A}$ and $p=0.016$ for $H N F 1 A$ I27L) ${ }^{\mathrm{b}} p=0.006$ for comparison of AA genotype vs GG genotype between women with and without GDM

${ }^{c}$ Differences in allele frequencies between women with and without GDM ( $p=0.008$ for $G C K-30 \mathrm{G} \rightarrow \mathrm{A}$ and $p=0.048$ for $H N F 1 A$ I27L) 
expressed as mean \pm SEM. Haplotype analysis was carried out using Haploview software 3.2 [33]. To correct for multiple testing, we permuted the data as implemented in Haploview version 3.2 [33]. We used 10,000 permutations, however, using more permutations gave the same results. This study was not designed to detect differences between genetic models. However, since we did not have predefined genetic models of the potential effect of these variants, we chose to present the data for additive, recessive and dominant models. Two-sided $p$ values less than 0.05 were considered statistically significant.

\section{Power calculation}

By studying a sample of 648 cases and 1,232 controls, the present study had more than $80 \%$ power, under a multiplicative model, to detect an effect size of 1.3 (as measured in terms of genotypic relative risk) when the frequency of the predisposing allele equalled $15 \%$ (for $\alpha=0.05$ ). When the predisposing allele frequency was $>30 \%$, the study had at least $80 \%$ power to detect an OR of 1.22 under a multiplicative model (for $\alpha=0.05$ ). Power calculations were performed using the Genetic Power Calculator (available at http://ibgwww.colorado.edu/ pshaun/gpc/) [34].

\section{Results}

\section{Subject characteristics}

Women with GDM were slightly older than pregnant nondiabetic controls $(32.3 \pm 0.2$ vs $30.5 \pm 0.1, p<0.0001)$. The genotype and allele frequency distributions of all polymorphisms studied are presented in Table 1.

$G C K-30 \mathrm{G} \rightarrow \mathrm{A}$

The GG, GA and AA genotype frequencies of the $G C K-30 \mathrm{G} \rightarrow \mathrm{A}$ polymorphism differed significantly between GDM and control women $(67.8,28.2$ and $4.0 \%$ vs $72.3,25.7$ and $2.0 \%$, respectively, $p=0.010$ ). In addition, the A allele was found to be more common in GDM women than among control subjects (OR 1.28, 95\% CI $1.06-1.53, p=0.008$, corrected $p$ value, $p=0.035$ ). Under a recessive model (AA vs GA+GG), the OR increased further to $2.12(95 \%$ CI $1.21-3.72, p=0.009)$. Using a dominant model, the OR for GDM in carriers of the GA or AA genotypes compared with carriers of the GG genotype was $1.24(95 \%$ CI $1.01-1.53, p=0.039)$. Of note, the ORs were almost the same, with overlapping 95\% CIs, when women who were positive for GAD65Ab, IA-2Ab or both (antibody measurements were not available for all subjects) were removed from the analyses (data not shown).

\section{HNF1A I27L}

The II, IL and LL genotype frequencies of the HNF1A I27L polymorphism differed significantly between GDM and control women $(39.4,48.5$ and $12.1 \%$ vs $46.1,41.8$ and $12.1 \%$, respectively, $p=0.016$ ). The $\mathrm{L}$ allele was slightly more frequent in GDM women than in controls (OR 1.16, $95 \%$ CI $1.001-1.34, p=0.048$, corrected $p$ value, $p=0.17$ ). However, the IL genotype was more frequent in GDM women than in controls, compared with the wild-type II genotype (OR 1.36, 95\% CI 1.10-1.67, $p=0.004$ ). In addition, under a dominant model [IL+LL vs II], the L allele conferred an increased risk of GDM (OR 1.31, 95\% CI 1.08-1.60, $p=0.007)$. As for the $G C K-30 \mathrm{G} \rightarrow \mathrm{A}$ polymorphism, the ORs and 95\% CIs remained almost the same when women who were positive for GAD65Ab, IA $-2 \mathrm{Ab}$ or both were excluded from the analyses (data not shown).

\section{$H N F 4 A$ variants}

The degree of linkage disequilibrium between HNF4A variants (rs2144908, rs2425637 and rs1885088) was estimated using $D^{\prime}$ and $r^{2}$ values. There was no evidence of linkage disequilibrium between these variants; $\mathrm{D}^{\prime}$ values were between 0.01 and 0.5 and $r^{2}$ values were between 0.0 and 0.01 .

The frequency of the A allele of the rs 2144908 variant, which is located 1,272 bp downstream of the primary beta cell promoter (P2) of $H N F 4 A$, did not differ significantly between GDM and controls (OR 1.14, 95\% CI 0.96-1.37, $p=0.14$ ).

Neither was there any difference in the frequency of the $\mathrm{T}$ allele of the rs2425637 variant, which is located 39,604 bp downstream of P2, between GDM and control women (OR 1.09, 95\% CI 0.95-1.24, $p=0.23$ ).

The intronic variant (rs1885088) is located $54,595 \mathrm{bp}$ downstream of the P2. Similar frequencies of the A allele were observed in women with GDM and control women (OR 0.96, 95\% CI 0.81-1.14, $p=0.66$ ).

\section{Discussion}

The key finding of the present study was that common variants in two MODY genes, $G C K$ and $H N F 1 A$, increase the risk of GDM.

\section{$G C K-30 \mathrm{G} \rightarrow \mathrm{A}$}

In the pancreatic islets, glucokinase plays a critical role in the regulation of insulin secretion by acting as a glucose sensor [35]. The $-30 \mathrm{G} \rightarrow \mathrm{A}$ variant in the beta-cell-specific promoter of the $G C K$ was shown to co-segregate with diabetes in a French family in which the proband was a woman with GDM [15]. Subsequently, it has been associated with reduced beta cell function in middle-aged 
Japanese-American men [36]. In addition, in women in the third trimester of pregnancy, the AA genotype led to a reduction in early-phase insulin secretion [37]. In a recent study of 755 pregnant women, the A allele was associated with increased fasting plasma glucose measured at 28 weeks of gestation in healthy Caucasian women from the UK [38]. In support of this, another recent study reported association of this polymorphism with elevated fasting and post-OGTT glucose levels as well as with impaired glucose regulation (i.e. type 2 diabetes, IGT and IFG) and features of the metabolic syndrome in Caucasians [21]. However, no association of the $-30 \mathrm{G} \rightarrow$ A variant with GDM was observed in two small studies that included women of Caucasian, black and oriental origin [39] or in American black women [40]. Interestingly, it has been demonstrated that the $\mathrm{A}$ allele increases the risk of coronary artery disease in individuals with and without type 2 diabetes [20] and it was also associated with an increased prevalence of type 2 diabetes in subjects with coronary artery disease [20].

In the present study, the A allele was associated with a modestly increased risk of GDM and this effect was more pronounced under a recessive mode of inheritance. The previously demonstrated deleterious effect of this polymorphism on beta cell function during pregnancy [37] might be a plausible explanation for the observed association, which is consistent with the key role of impaired beta cell function in the pathogenesis of GDM [6-8].

\section{$H N F 1 A$ I27L}

Defective insulin secretion is the hallmark of patients with HNF1A (i.e. MODY3) mutations [18]. The $\mathrm{I} 27 \mathrm{~L}$ polymorphism is located within the dimerisation domain of $H N F 1 A$ [41], and the amino acid isoleucine is conserved among several species, suggesting a potential functional importance of this residue [22]. Chiu et al. have reported association of the $\mathrm{I} 27 \mathrm{~L}$ polymorphism with lower first- and second-phase insulin secretion in glucose-tolerant subjects [22]. In line with this, we found a nominal association of the $\mathrm{L}$ allele of the $\mathrm{I} 27 \mathrm{~L}$ polymorphism with type 2 diabetes in Scandinavian/Canadian subjects, but this was not the case in the larger sample including also subjects from the US and Poland [27] or in a recent large study in the UK Caucasian population [26]. Moreover, we have recently observed an association of the $\mathrm{I} 27 \mathrm{~L}$ polymorphism with increased risk of type 2 diabetes in a large new Swedish case-control study [42]. This was supported by in vitro findings that the $\mathrm{L}$ allele was associated with decreased transcriptional activity in HeLa and INS-1 cells [42].

In keeping with the findings for the $G C K-30 \mathrm{G} \rightarrow \mathrm{A}$ variant, we observed a modest effect of the $\mathrm{L}$ allele of the HNF1A I27L polymorphism on the risk of GDM, which might be mediated by its effect on beta cell function [22]. It may be expected that individuals with a slight impairment in their beta cell function are more prone to deteriorated glucose tolerance when becoming insulin-resistant during pregnancy. It was, however, not possible to address a potential effect on beta cell function in the present study, as this would have required assessment of beta cell function prior to and during pregnancy. Unfortunately, we did not have this information. However, this finding should be interpreted with some caution since the difference in allele frequencies between GDM and controls was not statistically significant after correction for multiple comparisons.

\section{$H N F 4 A$ variants}

Somewhat surprisingly, variants in $H N F 4 A$, which have repeatedly been associated with a modestly increased risk of type 2 diabetes [23-25], were not associated with GDM in the present study. HNF4A is a member of the nuclear receptor family of transcription factors, which is expressed in several tissues, including the liver, gut, kidney and pancreas [43]. Whereas the expression of $H N F 4 A$ in the liver is mediated by a proximal promoter $(\mathrm{P} 1)$, its expression in beta cells is driven by an alternative beta cell promoter (P2) located $46 \mathrm{~kb}$ upstream of P1 [44, 45]. Mutations in the HNFIA and IPFI binding sites of the $\mathrm{P} 2$ promoter have been associated with MODY $1[44,45]$. The rs2144908, rs2425637 and rs1885088 variants, which are located downstream of the P2 promoter, were originally associated with type 2 diabetes in Finns [23]. In addition, the rs2144908 variant has been associated with type 2 diabetes in an Ashkenazi Jewish population [24] as well as in Caucasians from the UK [25]. Interestingly, the rs2144908 variant was also associated with reduced beta cell function (i.e. decreased acute insulin response to glucose and decreased disposition index) in unaffected Finnish offspring of parents with type 2 diabetes [23]. In the present study, there was no evidence for association of these variants with GDM. This may suggest that the studied variants in the HNF4A gene have no major impact on predisposition to GDM. However, it should be stressed that a smaller effect $(\mathrm{OR}<1.22-1.27$ depending on the allele frequency) of these variants on the risk of GDM could have been missed. Indeed, the present study had adequate power to detect the ORs (1.23-1.46) reported for type 2 diabetes in the original studies $[23,24]$, but not the ORs $(1.14-1.15)$ reported in Caucasians from the UK and Denmark in recent large studies $[25,46]$. Consistent with the other studies, these three variants were not in linkage disequilibrium in our study and the frequencies of the minor alleles in controls were comparable to that reported in other populations $[23-25,46]$.

In conclusion, the $-30 \mathrm{G} \rightarrow \mathrm{A}$ polymorphism of the betacell-specific promoter of $G C K$ and the $127 \mathrm{~L}$ polymorphism of HNF1A seem to increase the risk of GDM in Scandinavian women, suggesting a role of common variants that are known to affect beta cell function in the aetiology of GDM. However, to demonstrate a direct effect on beta cell function more studies are required, with assessment of beta cell function prior to and during pregnancy in carriers of these polymorphisms. 
Acknowledgements This work was supported by grants from the Swedish Research Council, the Söderberg Foundation, Lundberg Foundation and Novo Nordisk Foundation and grants to the DiPiS study. We thank all the subjects for their participation, and the DiPiS research group. We are indebted to M. Svensson, A. Berglund and A. Nilsson for excellent technical assistance.

\section{References}

1. Metzger BE, Coustan DR (1998) Summary and recommendations of the fourth international workshop-conference on gestational diabetes mellitus. Diabetes Care 21(Suppl 2): B161-B167

2. Aberg A, Rydhstroem H, Frid A (2001) Impaired glucose tolerance associated with adverse pregnancy outcome: a population-based study in southern Sweden. Am J Obstet Gynecol 184:77-83

3. King H (1998) Epidemiology of glucose intolerance and gestational diabetes in women of childbearing age. Diabetes Care 21(Suppl 2):B9-B13

4. Ferrara A, Kahn HS, Quesenberry CP, Riley C, Hedderson MM (2004) An increase in the incidence of gestational diabetes mellitus: Northern California, 1991-2000. Obstet Gynecol 103:526-533

5. Dabelea D, Snell-Bergeon JK, Hartsfield CL, Bischoff KJ, Hamman RF, McDuffie RS (2005) Increasing prevalence of gestational diabetes mellitus (GDM) over time and by birth cohort: Kaiser Permanente of Colorado GDM Screening Program. Diabetes Care 28:579-584

6. Buchanan TA (2001) Pancreatic B-cell defects in gestational diabetes: implications for the pathogenesis and prevention of type 2 diabetes. J Clin Endocrinol Metab 86:989-993

7. Xiang AH, Peters RK, Trigo E, Kjos SL, Lee WP, Buchanan TA (1999) Multiple metabolic defects during late pregnancy in women at high risk for type 2 diabetes. Diabetes 48:848-854

8. Osei K, Gaillard TR, Schuster DP (1998) History of gestational diabetes leads to distinct metabolic alterations in nondiabetic African-American women with a parental history of type 2 diabetes. Diabetes Care 21:1250-1257

9. Fajans SS, Bell GI, Polonsky KS (2001) Molecular mechanisms and clinical pathophysiology of maturity-onset diabetes of the young. N Engl J Med 345:971-980

10. Frayling TM, Evans JC, Bulman MP et al (2001) Beta-cell genes and diabetes: molecular and clinical characterization of mutations in transcription factors. Diabetes 50(Suppl 1): S94-S100

11. Pruhova S, Ek J, Lebl J et al (2003) Genetic epidemiology of MODY in the Czech republic: new mutations in the MODY genes HNF-4alpha, GCK and HNF-1alpha. Diabetologia 46:291-295

12. Stoffel M, Bell KL, Blackburn CL et al (1993) Identification of glucokinase mutations in subjects with gestational diabetes mellitus. Diabetes 42:937-940

13. Saker PJ, Hattersley AT, Barrow B et al (1996) High prevalence of a missense mutation of the glucokinase gene in gestational diabetic patients due to a founder-effect in a local population. Diabetologia 39:1325-1328

14. Ellard S, Beards F, Allen LI et al (2000) A high prevalence of glucokinase mutations in gestational diabetic subjects selected by clinical criteria. Diabetologia 43:250-253

15. Zouali H, Vaxillaire M, Lesage S et al (1993) Linkage analysis and molecular scanning of glucokinase gene in NIDDM families. Diabetes 42:1238-1245

16. Weng J, Ekelund M, Lehto $M$ et al (2002) Screening for MODY mutations, GAD antibodies, and type 1 diabetesassociated HLA genotypes in women with gestational diabetes mellitus. Diabetes Care 25:68-71
17. Thomson KL, Gloyn AL, Colclough K et al (2003) Identification of 21 novel glucokinase (GCK) mutations in UK and European Caucasians with maturity-onset diabetes of the young (MODY). Hum Mutat 22:417-421

18. Lehto M, Tuomi T, Mahtani MM et al (1997) Characterization of the MODY3 phenotype. Early-onset diabetes caused by an insulin secretion defect. J Clin Invest 99:582-591

19. Gragnoli C, Stanojevic V, Gorini A, Von Preussenthal GM, Thomas MK, Habener JF (2005) IPF-1/MODY4 gene missense mutation in an Italian family with type 2 and gestational diabetes. Metabolism 54:983-988

20. Marz W, Nauck M, Hoffmann MM et al (2004) G(-30)A polymorphism in the pancreatic promoter of the glucokinase gene associated with angiographic coronary artery disease and type 2 diabetes mellitus. Circulation 109:2844-2849

21. Rose CS, Ek J, Urhammer SA et al (2005) A -30G $>$ A polymorphism of the $\{$ beta $\}$-cell-specific glucokinase promoter associates with hyperglycemia in the general population of whites. Diabetes 54:3026-3031

22. Chiu KC, Chuang LM, Chu A, Wang M (2003) Transcription factor 1 and beta-cell function in glucose-tolerant subjects. Diabet Med 20:225-230

23. Silander K, Mohlke KL, Scott LJ et al (2004) Genetic variation near the hepatocyte nuclear factor-4 alpha gene predicts susceptibility to type 2 diabetes. Diabetes 53:1141-1149

24. Love-Gregory LD, Wasson J, Ma J et al (2004) A common polymorphism in the upstream promoter region of the hepatocyte nuclear factor- 4 alpha gene on chromosome $20 \mathrm{q}$ is associated with type 2 diabetes and appears to contribute to the evidence for linkage in an Ashkenazi Jewish population. Diabetes 53:1134-1140

25. Weedon MN, Owen KR, Shields B et al (2004) Common variants of the hepatocyte nuclear factor-4alpha $\mathrm{P} 2$ promoter are associated with type 2 diabetes in the U.K. population. Diabetes 53:3002-3006

26. Weedon MN, Owen KR, Shields B et al (2005) A large-scale association analysis of common variation of the HNF1alpha gene with type 2 diabetes in the U.K. Caucasian population. Diabetes 54:2487-2491

27. Winckler W, Burtt NP, Holmkvist J et al (2005) Association of common variation in the HNF1 \{alpha\} gene region with risk of type 2 diabetes. Diabetes 54:2336-2342

28. Winckler W, Graham RR, de Bakker PI et al (2005) Association testing of variants in the hepatocyte nuclear factor 4alpha gene with risk of type 2 diabetes in 7,883 people. Diabetes 54: 886-892

29. Lind T, Phillips PR (1991) Influence of pregnancy on the 75-g OGTT. A prospective multicenter study. The Diabetic Pregnancy Study Group of the European Association for the Study of Diabetes. Diabetes 40(Suppl 2):8-13

30. Shaat N, Ekelund M, Lernmark A et al (2005) Association of the E23K polymorphism in the KCNJ11 gene with gestational diabetes mellitus. Diabetologia 48:2544-2551

31. Shaat N, Ekelund M, Lernmark A et al (2004) Genotypic and phenotypic differences between Arabian and Scandinavian women with gestational diabetes mellitus. Diabetologia 47:878-884

32. Lernmark B, Elding-Larsson H, Hansson G, Lindberg B, Lynch K, Sjoblad S (2004) Parent responses to participation in genetic screening for diabetes risk. Pediatr Diabetes 5:174-181

33. Barrett JC, Fry B, Maller J, Daly MJ (2005) Haploview: analysis and visualization of LD and haplotype maps. Bioinformatics 21:263-265

34. Purcell S, Cherny SS, Sham PC (2003) Genetic Power Calculator: design of linkage and association genetic mapping studies of complex traits. Bioinformatics 19:149-150. Available from http://ibgwww.colorado.edu/ pshaun/gpc/. Accessed 21 February 2006

35. Matschinsky F, Liang Y, Kesavan P et al (1993) Glucokinase as pancreatic beta cell glucose sensor and diabetes gene. J Clin Invest 92:2092-2098 
36. Stone LM, Kahn SE, Fujimoto WY, Deeb SS, Porte D Jr (1996) A variation at position -30 of the beta-cell glucokinase gene promoter is associated with reduced beta-cell function in middle-aged Japanese-American men. Diabetes 45:422-428

37. Zaidi FK, Wareham NJ, McCarthy MI et al (1997) Homozygosity for a common polymorphism in the islet-specific promoter of the glucokinase gene is associated with a reduced early insulin response to oral glucose in pregnant women. Diabet Med 14:228-234

38. Weedon MN, Frayling TM, Shields B et al (2005) Genetic regulation of birth weight and fasting glucose by a common polymorphism in the islet cell promoter of the glucokinase gene. Diabetes 54:576-581

39. Allan CJ, Argyropoulos G, Bowker M et al (1997) Gestational diabetes mellitus and gene mutations which affect insulin secretion. Diabetes Res Clin Pract 36:135-141

40. Chiu KC, Go RC, Aoki M et al (1994) Glucokinase gene in gestational diabetes mellitus: population association study and molecular scanning. Diabetologia 37:104-110

41. Ryffel GU (2001) Mutations in the human genes encoding the transcription factors of the hepatocyte nuclear factor (HNF)1 and HNF4 families: functional and pathological consequences. J Mol Endocrinol 27:11-29
42. Holmkvist J, Cervin C, Almgren P, Lyssenko V, Cilio C, Groop $\mathrm{L}$ (2005) Common variants in the HNF-1a gene increase susceptibility to type 2 diabetes [abstract]. Diabetologia 48 (Suppl 11):A127

43. Duncan SA, Manova K, Chen WS et al (1994) Expression of transcription factor HNF-4 in the extraembryonic endoderm, gut, and nephrogenic tissue of the developing mouse embryo: HNF-4 is a marker for primary endoderm in the implanting blastocyst. Proc Natl Acad Sci USA 91:7598-7602

44. Thomas H, Jaschkowitz K, Bulman M et al (2001) A distant upstream promoter of the HNF-4alpha gene connects the transcription factors involved in maturity-onset diabetes of the young. Hum Mol Genet 10:2089-2097

45. Hansen SK, Parrizas M, Jensen ML et al (2002) Genetic evidence that HNF-1alpha-dependent transcriptional control of HNF-4alpha is essential for human pancreatic beta cell function. J Clin Invest 110:827-833

46. Hansen SK, Rose CS, Glumer C et al (2005) Variation near the hepatocyte nuclear factor (HNF)-4alpha gene associates with type 2 diabetes in the Danish population. Diabetologia 48: $452-458$ 